\title{
Correction to: When kidneys and lungs suffer together
}

\author{
Claudio Sorino $^{1}$ (D) Nicola Scichilone ${ }^{2} \cdot$ Claudio Pedone $^{3} \cdot$ Stefano Negri $^{4} \cdot$ Dina Visca $^{5} \cdot$ Antonio Spanevello $^{4,5}$
}

Published online: 16 September 2019

(c) Italian Society of Nephrology 2019

\section{Correction to: Journal of Nephrology}

\section{https://doi.org/10.1007/s40620-018-00563-1}

Given names of all the authors have been interchanged with family names.

Sorino Claudio, Scichilone Nicola, Pedone Claudio, Negri Stefano, Visca Dina, Spanevello Antonio

should be changed into

Claudio Sorino, Nicola Scichilone, Claudio Pedone, Stefano Negri, Dina Visca, Antonio Spanevello

The original article has been corrected.

Publisher's Note Springer Nature remains neutral with regard to jurisdictional claims in published maps and institutional affiliations.

The original article can be found online at https://doi.org/10.1007/ s40620-018-00563-1.

Claudio Sorino

claudiosorino@libero.it

1 Division of Pulmonology, S. Anna Hospital, Como, Italy

2 Biomedical Department of Internal and Specialist Medicine, University of Palermo, Palermo, Italy

3 Chair of Geriatrics, University Campus Bio-Medico, Rome, Italy

4 University of Insubria, Varese, Italy

5 Division of Pulmonary Rheabilitation, Maugeri Care and Research Institute, IRCCS, Tradate, Italy 